Diagnostico socioeconômico, ambiental e avaliação das características morfométricas da microbacia do Córrego Alegria em Uberaba-MG José Luiz Rodrigues Torres, Tobias Rodrigues da Silva, Francienne Góis Oliveira, Gustavo Silva Araújo, Adelar José Fabian

\title{
DIAGNOSTICO SOCIOECONÔMICO, AMBIENTAL E AVALIAÇÃO DAS CARACTERÍSTICAS MORFOMÉTRICAS DA MICROBACIA DO CÓRREGO ALEGRIA EM UBERABA - MG
}

\author{
Diagnosis socioeconomic, environmental and evaluation of the morphometric \\ characteristics of stream happiness's microbasin in Uberaba - MG
}

José Luiz Rodrigues Torres

Prof. Dr. Produção Vegetal - CEFET-Uberaba-MG

jlrtorres@terra.com.br Tobias Rodrigues da Silva Francienne Góis Oliveira

Gustavo Silva Araújo

Tecnólogos em Gestão Ambiental pelo CEFET-Uberaba-MG

Adelar José Fabian

Prof. MSc. Solos - CEFET-Uberaba-MG

Artigo recebido para publicação em 11/04/2007 e aceito para publicação em 08/08/2007

RESUMO: Com objetivo de diagnosticar a deterioração socioeconômica, ambiental e avaliar as características morfométricas da microbacia do Córrego Alegria, visitou-se a área de estudo, aplicando-se questionários numa amostra da população local. A deterioração social (S) é de $46 \%$, considerado médio, pois o nível de escolaridade, alimentação e as condições de trabalho são bons na região. Para o fator econômico (E) obteve-se 48 \%, valor elevado, pois as propriedades são de média a alta produtividade, com renda média variando de 5 a 15 salários mínimos, além de contar com assistência técnica e ser cooperados. Para o fator tecnológico (T) obteve-se $32 \%$, valor baixo, devido ao tipo de exploração local. Para o fator sócioeconômico $(S+E+T)$ obteve-se $44 \%$, considerado alto, que deveria limitar as condições de vida do produtor, porém isto não é observado. A deterioração ambiental calculada é de 15\%, abaixo do esperado, sendo este valor justificado pela constante fiscalização e investimentos na recuperação da área, principalmente após o acidente ferroviário ocorrido em junho de 2003. A microbacia tem uma forma mais alongada, sendo comprovado pelo Ic de 060, Kc de 0,98 e Kf de 0,15, além da Dd de 1,10 km/ $\mathrm{km}^{2}$ e a declividade da bacia de 1,20\%. Estes valores associados mostram uma área sem problemas de enchentes e erosões ao longo do Córrego. Os índices obtidos ainda não demonstram uma deterioração ambiental elevada.

Palavras-chave: Deterioração ambiental, Microbacia, Análise morfométricas, Cerrado.

ABSTRACT: With objective of to diagnose the deterioration socioeconomic, environmental and to evaluate the morphometric characteristics of the microbasin of the Stream Happiness's, the study area was visited, applying itself questionnaires in a sample of the local population. The social deterioration (S) it is of $46 \%$, considered medium, because the education level, feeding and the work 
conditions are good in the region. For the economical factor (E) it was obtained 48\%, high value, because the properties are of average the high productivity, with medium income varying from 5 to 15 minimum wages, besides counting with technical support and to be cooperated. For the technological factor (T) it was obtained 32\%, low value, due to the type of local exploration. For the socioeconomic factor $(S+E+T)$ it was obtained $44 \%$, considered loud, that it should limit the conditions of life of the producer, however this is not observed. The calculated environmental deterioration is of $15 \%$, below the expected, being this justified value for the constant fiscalization and investments in the recovery of the area, mainly after the rail accident happened in June of 2003. The microbasin has a more prolonged form, being proven for Ic 060, Kc 0,98 and $\mathrm{Kf}$ of 0,15, besides Dd of $1,10 \mathrm{~km} / \mathrm{km}^{2}$ and the declivity of the 1,20\% basin. These associated values show an area without problems of inundations and erosions along the Stream. The indexes obtained don't still demonstrate a high environmental deterioration.

Keywords: Environmental deterioration, Microbasin, Morphometric analysis, Cerrado.

\section{INTRODUÇÃO}

A bacia hidrográfica é uma unidade geomorfológica fundamental da superfície terrestre, considerada como principal unidade fisiográfica do terreno, porque suas características governam, no seu interior, todo o fluxo superficial da água. Constitui, portanto, uma área ideal para o planejamento integrado do manejo dos recursos naturais no meio ambiente por ela definido. A noção de bacia obriga, naturalmente, a existência de divisores d'água, cabeceiras ou nascentes, cursos d'água principais, afluentes, subafluentes, bem como, uma hierarquização dos canais escoadouros e uma distribuição dos solos predominantes (TUCCI, 2004).

As abordagens de planejamento e gestão que utilizam as bacias hidrográficas como unidades básicas de trabalho, são adequadas para compatibilização da produção agrícola com a preservação ambiental, por que as considera como unidades geográficas naturais com suas características biofísicas e sociais integradas (SOUZA e FERNANDES, 2000). De um modo geral, as abordagens de planejamento das atividades antrópicas e do uso dos recursos naturais, com base em modelos clássicos, têm falhado por dissociarem as questões socioeconômicas dos aspectos ambientais inerentes, além disso, falta o conhecimento das dinâmicas ambientais, socioeconômicas e dos con- flitos que por ventura existam entre as metas de desenvolvimento e a capacidade de suporte dos ecossistemas (PIRES e SANTOS, 1995).

A implantação de uma proposta de manejo integrado de uma microbacia hidrográfica passa primeiramente pela elaboração de um diagnóstico básico, os quais levantam todos os problemas da bacia, para analise dos conflitos e recomendação de soluções em todos os níveis (VIANA et al., 2001). Rocha (1997), Rocha e Kurts (2001) destacam que os diagnósticos mais importantes são o físico-conservacionista, o sócio-econômico e o ambiental, pois estes interagem entre si, podendo assim ser feito um levantamento das deteriorações que ocorrem na área, em percentagem, mostrando o grau de deterioração ambiental das variáveis analisadas.

Cruz (2003) confeccionou o diagnóstico ambiental da bacia hidrográfica do rio Uberaba e identificou áreas a serem recuperadas, áreas que estão preservadas, realizaram a caracterização ambiental ponderando as ações a serem implementadas num plano de gerenciamento e observou também que a bacia hidrográfica encontra-se bastante degradada. Alguns diagnósticos ambientais preliminares vêm sendo desenvolvidos nas microbacias da área de proteção ambiental (APA) do rio Uberaba e divulgados em eventos locais, regionais, nacionais e in- 
Diagnostico socioeconômico, ambiental e avaliação das características morfométricas da microbacia do Córrego Alegria em Uberaba-MG José Luiz Rodrigues Torres, Tobias Rodrigues da Silva, Francienne Góis Oliveira, Gustavo Silva Araújo, Adelar José Fabian

ternacionais (FABIAN et al., 2002; FABIAN e TORRES, 2003; SANTOS et al., 2005; SILVA et al., 2005; ARAÚJO et al., 2005; MARTINS et al. 2005), sendo que em todos estes estudos, a APA se encontra num processo de deterioração ambiental crescente.

No estudo da deterioração da ambiência das microbacias vários parâmetros podem ser utilizados para subsidiar uma análise mais detalhada, especialmente algumas características físicas da bacia, tais como: área e comprimento da bacia, comprimento de ravinas, densidade de drenagem, declividade média da bacia e coeficiente de rugosidade (ALCANTARA e AMORIM, 2005), dentre outros. Para Rocha e Kurtz (2001) existem inúmeros parâmetros que definem os tipos de rede, padrões ou sistemas de drenagem, os quais caracterizam, por conseguinte, as bacias, microbacias e sub-bacias hidrográficas. Entre estes, os parâmetros que mais se relacionam com a deterioração ambiental são: comprimento das ravinas, densidade de drenagem, índice de circularidade, índice de forma, declividade média da bacia, coeficiente de rugosidade. Baseados nesses fatores, este estudo teve como objetivo avaliar as deteriorações da ambiência e analisar morfométricamente a microbacia do córrego Alegria, para que possam servir de subsídio para o planejamento ambiental da área.

\section{MATERIAIS E MÉTODOS}

\section{Caracterização da microbacia}

O estudo foi realizado no município de Uberaba-MG localizado no Triângulo Mineiro, na latitude Sul 19 45’ 27 “e longitude Oeste 47 55' 36", numa área inserida dentro da área de proteção ambiental (APA) do rio Uberaba. A sede do Município está a $764 \mathrm{~m}$ de altitude, sendo que a altitude máxima é de $1.031 \mathrm{~m}$ (Serra de Ponte Alta) e a mínima $522 \mathrm{~m}$ (divisa com o Estado de São Paulo), ocupando uma área de 4.536,63 $\mathrm{Km}^{2}$ (Figura 1), dos quais apenas $256 \mathrm{Km}^{2}$ são ocupados pelo perímetro urbano (UBERABA, 2004).

A microbacia em estudo situa-se na região central da área de proteção ambiental do rio Uberaba (APA) e possui uma área total de 1.539,42 ha, correspondendo a 2,92 \% da área total da bacia (Figura 2). $\mathrm{O}$ ponto de menor cota, localizado na foz com o rio Uberaba, está numa altitude de $800 \mathrm{~m}$ e o maior na altitude $900 \mathrm{~m}$, portanto, com uma amplitude de 100 $\mathrm{m}$. A soma total de todos os seus cursos d'água atinge $17.104 \mathrm{~m}$ de comprimento medidos no talvegue. $\mathrm{O}$ curso principal, da nascente à foz, mede $8.526 \mathrm{~m}$. O número de nascentes perene totaliza 13, o que representam 2,8\% das nascentes contidas em toda APA (SEMEA, 2004).

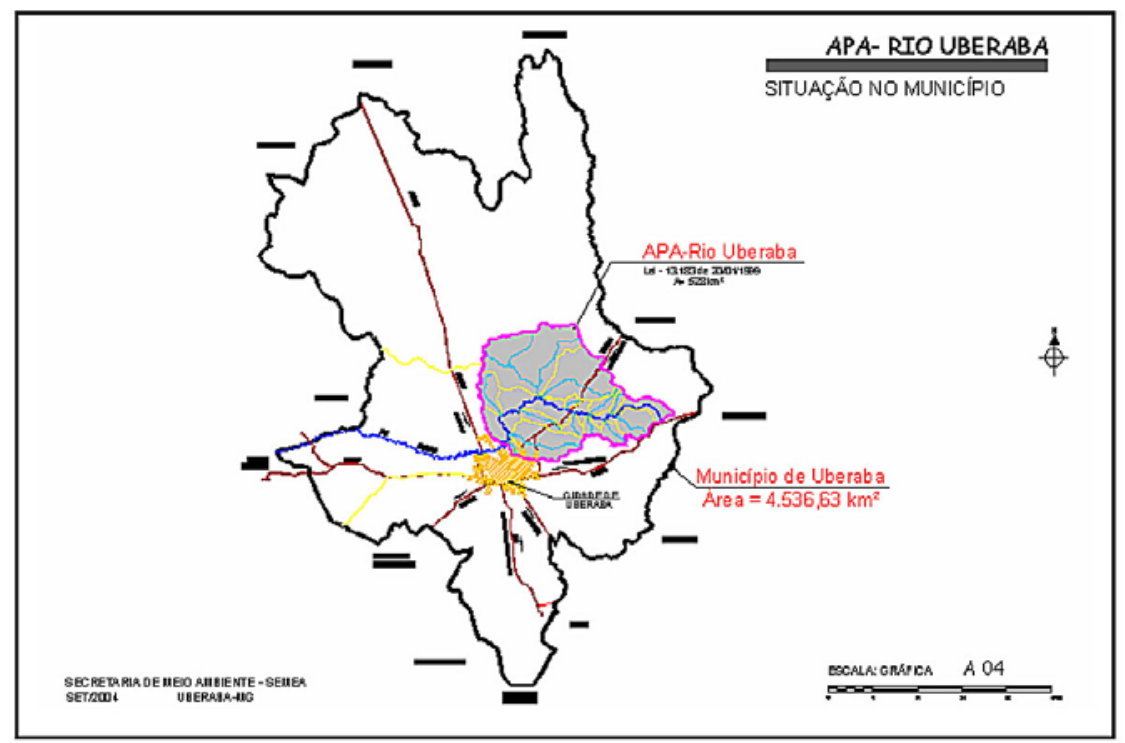

Figura 1. O município de Uberaba-MG e sua Área de proteção ambiental (APA) do rio Uberaba (SEMEA, 2004). 
Algumas áreas do Triângulo Mineiro apresentam temperatura média anual entre $20^{\circ} \mathrm{C}$ e $22^{\circ} \mathrm{C}$ e nos meses mais frios em torno de $18^{\circ} \mathrm{C}$. Com média das máximas de $29,0^{\circ} \mathrm{C}$ e das mínimas de $16,9^{\circ} \mathrm{C}$, e insolação em torno de 360,4 horas (Tabela 1) (ABDALA, 2005). Segundo Gomes (1982), o regime pluviométrico da região do Triângulo Mineiro caracteriza-se por um período chuvoso de outubro até março ou abril com precipitação anual variando entre $1.300 \mathrm{~mm}$ e $1.700 \mathrm{~mm}$. A média anual da umidade relativa fica entre 65 e $75 \%$, com valor máximo de 81\% em dezembro e mínimo de 52\% em agosto .

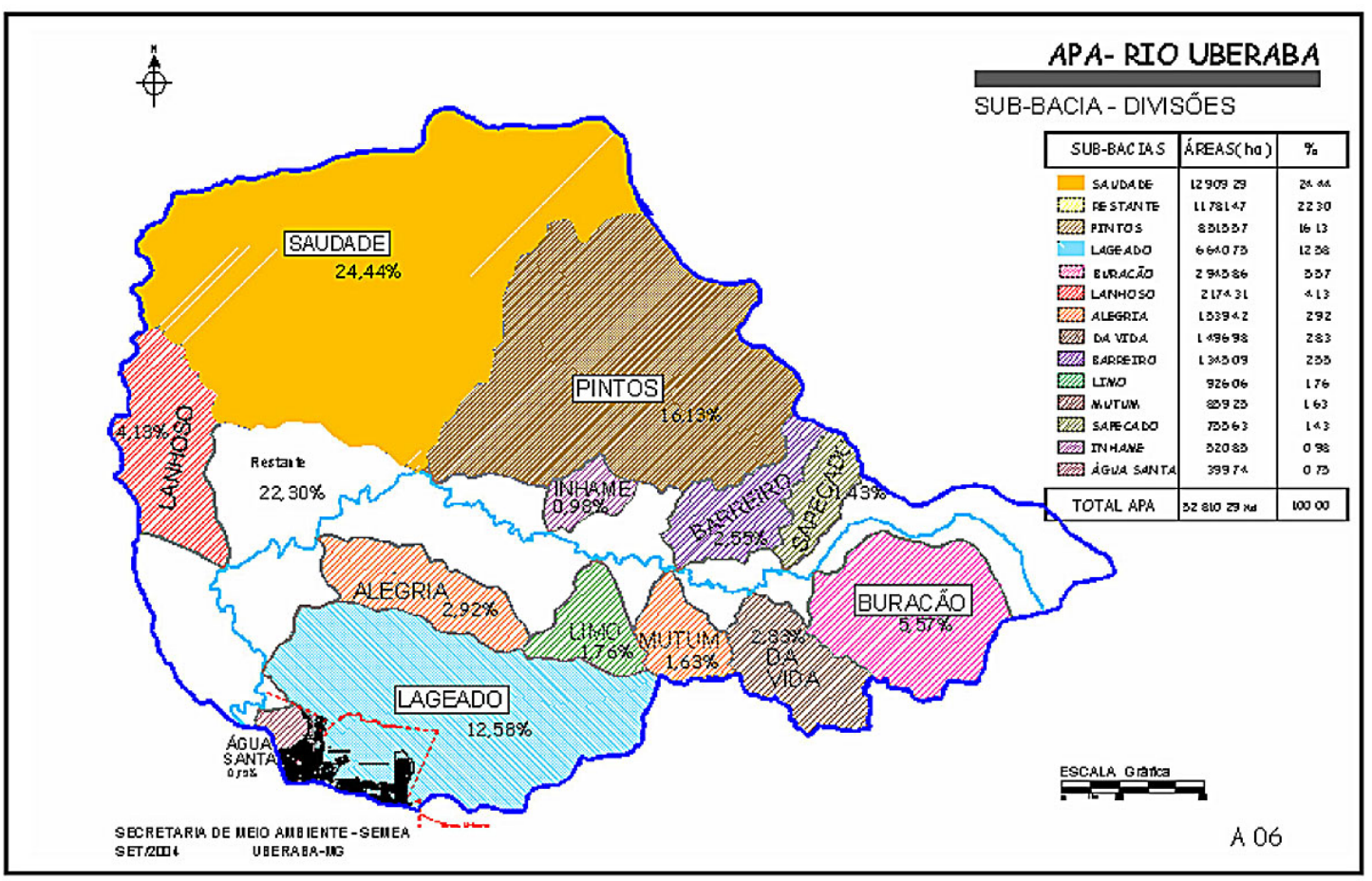

Figura 2. Microbacia do córrego Alegria, localizado na APA do Rio Uberaba (SEMEA, 2004).

Tabela 1. Dados climáticos da região de Uberaba do período de 1995 a 2004, extraidos do acervo de dados da Estação climatológica de Uberaba INMET/EPAMIG.

\begin{tabular}{|c|c|c|c|c|c|}
\hline \multirow[t]{2}{*}{ ANO } & Temperatura Máxima & Temperatura Mínima & Precipitação Anual & Insolação Média & Umidade Relativa \\
\hline & \multicolumn{2}{|c|}{ 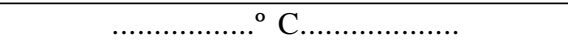 } & ......mm........ & .......h.......... & .....\%...... \\
\hline 1995 & 29,2 & 16,2 & 1392,5 & 344,5 & 63,3 \\
\hline 1996 & 28,8 & 15,8 & 1654,5 & 341,2 & 67,0 \\
\hline 1997 & 28,5 & 17,0 & 1636,9 & 363,6 & 66,3 \\
\hline 1998 & 29,9 & 17,5 & 1631,6 & 363,5 & 67,3 \\
\hline 1999 & 29,7 & 17,0 & 1463,2 & 373,1 & 64,3 \\
\hline 2000 & 29,3 & 16,7 & 2088,9 & 368,0 & 66,1 \\
\hline 2001 & 29,7 & 16,8 & 1249,1 & 370,4 & 64,4 \\
\hline 2002 & 30,3 & 17,5 & 1606,2 & 370,5 & 62,6 \\
\hline 2003 & 25,1 & 17,0 & 1728,8 & 362,1 & 63,6 \\
\hline 2004 & 29,0 & 17,4 & 1944,0 & 346,6 & 63,8 \\
\hline Médias & 29,0 & 16,9 & 1639,6 & 360,4 & 64,9 \\
\hline
\end{tabular}

Modificado de Abdala (2005) 
Diagnostico socioeconômico, ambiental e avaliação das características morfométricas da microbacia do Córrego Alegria em Uberaba-MG José Luiz Rodrigues Torres, Tobias Rodrigues da Silva, Francienne Góis Oliveira, Gustavo Silva Araújo, Adelar José Fabian

Quanto à cobertura vegetal na microbacia do córrego Alegria, existe 554,59 ha de área coberta com vegetação nativa, significando 37,04\% da área desta microbacia, conforme imagem de satélite LANDSAT-7 de outubro de 2003 (Figura 3, área verde), destes, 202,78 ha são consideradas área de preservação permanente (APP), sendo que a atividade produtiva predominante é a bovinocultura leiteira (SEMEA, 2004).

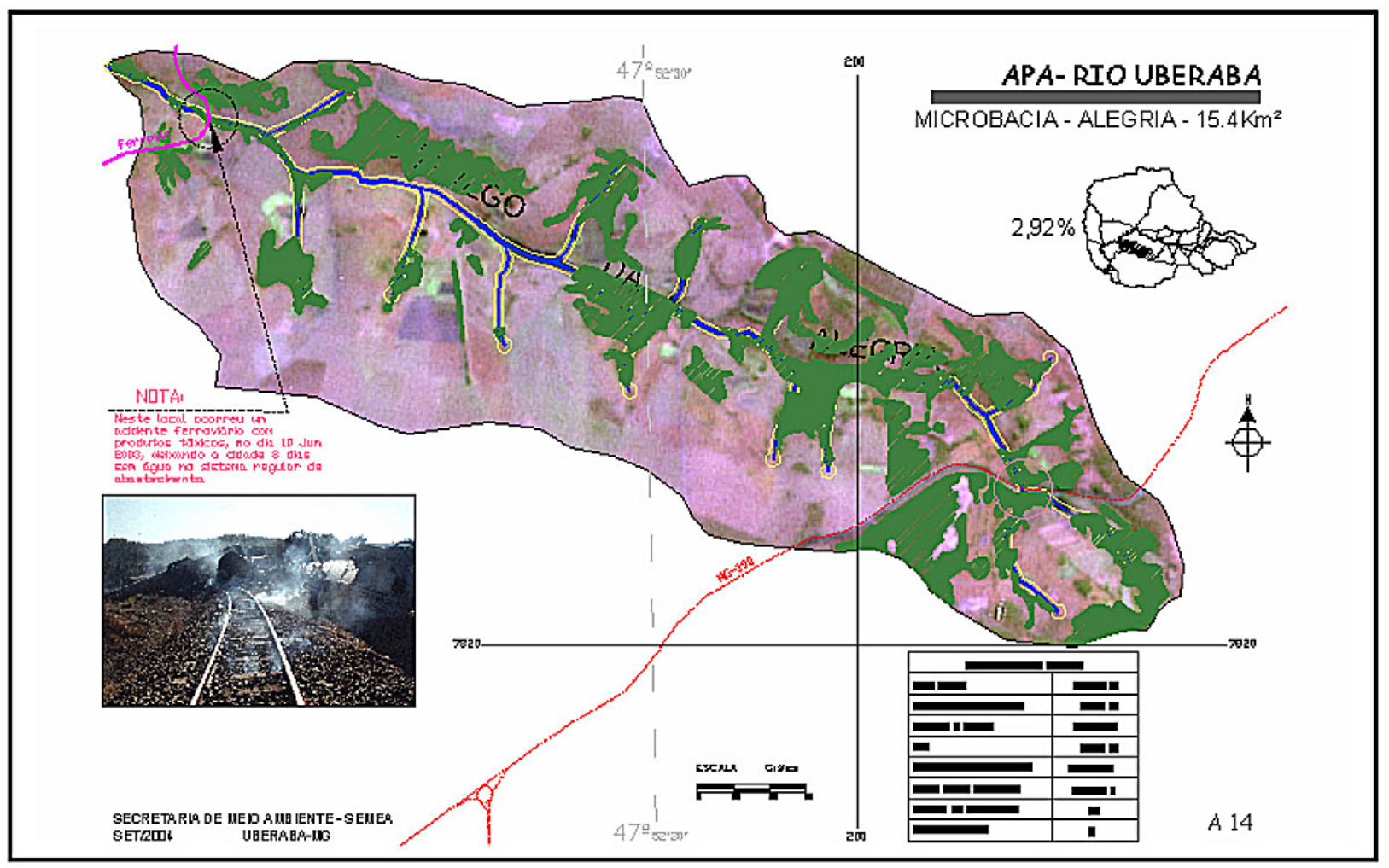

Figura 3. Microbacia do córrego Alegria, destacando as áreas verdes (cobertura vegetal) e o local onde ocorreu o acidente em 10.06.2003, inviabilizando o consumo da água do rio Uberaba por um período de 10 dias (SEMEA, 2004).

Segundo Nishiyama (1989), o município de Uberaba faz parte da unidade de relevo do planalto arenítico basáltico da Bacia do Paraná. Os solos são muito variados, a maioria apresentando textura média, sendo classificados de uma forma geral como Latossolos de diferentes graus de fertilidade. Segundo a Embrapa (1982), os solos predominantes na região do Triângulo Mineiro são os Latossolos VermelhoEscuro (66,79\% da área total), e Latossolo Roxo $(17,71 \%)$.

\section{Diagnóstico socioeconômico e ambiental}

Numa amostra da população da microbacia do Córrego Alegria foram aplicados os questionários adaptados do CIDIAT (Centro Interamericano de desenvolvimento Integral de Águas y Tierras) por Rocha (1997) e Rocha e Kurts (2003), que tem como base a Matriz de Interação de Leopold, os quais avaliam os fatores: social, econômica, socioeconômica, tecnológica e ambiental. Através dos valores obtidos foram calculadas as porcentagens de deterioração de cada fator (Tabela 2). Para o diagnóstico ambiental foram utilizados vinte e um indicadores de qualidade ambiental. Estes foram aplicados em cinco propriedades que compõem a microbacia, que ocupam juntas cerca de $75 \%$ da área, porém diferindo entre si quanto ao uso dos recursos naturais. 
Diagnostico socioeconômico, ambiental e avaliação das características morfométricas da microbacia do Córrego Alegria em Uberaba-MG José Luiz Rodrigues Torres, Tobias Rodrigues da Silva, Francienne Góis Oliveira, Gustavo Silva Araújo, Adelar José Fabian

Tabela 2. Variáveis analisadas nos questionários aplicados na população local.

\begin{tabular}{ll}
\hline FATOR & VARIÁVEIS \\
\hline Social & Demográfica; habitação; consumo de alimento; salubridade rural e participação em organização. \\
Econômico & Produção; animais de trabalho; animais de produção; comercialização, crédito e rendimento. \\
Tecnológico & Tecnologia; maquinário e industrialização rural. \\
\hline
\end{tabular}

\section{A caracterização morfométrica da microbacia}

As caracterizações físicas e morfométricas foram realizadas sobre uma carta topográfica do IBGE (Folha Uberaba) na escala 1:100.000 e a imagem Landsat 7 do Sensor ETM+, obtida em 11/10/2002, bandas Tm3, Tm4 e Tm7 (SEMEA, 2004). Utilizaram-se os índices apresentados em Christofoletti (1969; 1974), dentre eles podem ser destacados.

O coeficiente de compacidade (Kc) ou índice de Gravelius relaciona a forma da bacia com um círculo. Constitui a relação entre o perímetro da bacia e a circunferência de um círculo de área igual à da bacia (LIMA et al. 1998). O Kc foi determinado baseado na seguinte equação:

$$
K c=0,28 \frac{P}{\sqrt{A}}
$$

sendo: Kc o coeficiente de compacidade, $\mathrm{P}$ o perímetro (m) e A a área de drenagem $\left(\mathrm{m}^{2}\right)$.

O fator forma (F) relaciona a forma da bacia com a de um retângulo, correspondendo à razão entre a largura média e o comprimento axial da bacia (da foz ao ponto mais longínquo do espigão). Villela e Mattos (1975) destacam que a forma da bacia, bem como a forma do sistema de drenagem, pode ser influenciada por algumas características, principalmente pela geologia. Podem atuar também sobre alguns processos hidrológicos ou sobre o comportamento hidrológico da bacia. O fator de forma (F) foi determinado, utilizando-se a seguinte equação:

$$
F=\frac{A}{L^{2}}
$$

sendo o F: fator de forma, A a área de drenagem $\left(\mathrm{m}^{2}\right)$, L o comprimento do eixo da bacia $(\mathrm{m})$.
O índice de circularidade, simultaneamente ao coeficiente de compacidade, tende para a unidade à medida que a bacia se aproxima da forma circular e diminui à medida que a forma torna alongada. Pode ser calculado através da seguinte equação:

$$
I C=\frac{12,57 * A}{p^{2}}
$$

onde que IC é o índice de circularidade, A a área de drenagem $\left(\mathrm{m}^{2}\right)$ e $\mathrm{P}$ o perímetro (m).

A densidade de drenagem (Dd) estima a maior ou menor velocidade com que a água deixa a bacia hidrográfica, sendo, assim, o índice que indica o grau de desenvolvimento do sistema de drenagem, ou seja, fornece uma indicação da eficiência da drenagem da bacia, sendo expressa pela relação entre o somatório dos comprimentos de todos os canais da rede - sejam eles perenes, intermitentes ou temporários - e a área total da bacia (CARDOSO et al. 2006). O índice foi determinado utilizando a equação:

$$
\operatorname{Dd}=\frac{\mathrm{L}_{\mathrm{t}}}{\mathrm{A}}
$$

sendo Dd a densidade de drenagem $(\mathrm{km} /$ $\left.\mathrm{km}^{2}\right), \mathrm{L}_{\mathrm{t}}$ comprimento total de todos os canais ( $\mathrm{km}$ ) e A a área de drenagem $\left(\mathrm{km}^{2}\right)$.

A ordem dos cursos d'água foi determinada seguindo a classificação proposta por Strahler (1957), em que os canais sem tributários são designados de primeira ordem. Estas classes receberam um valor referente ao grau de ordenação a que pertenciam os canais dispostos na carta base tornando possível sua hierarquização.Segundo as Leis de Horton (1945), a ordem do curso de água é uma medida da ramificação dentro de uma bacia. Um curso de água de primeira ordem é um tributário sem ramificações; um curso de água de segunda ordem é um tributário formado 
Diagnostico socioeconômico, ambiental e avaliação das características morfométricas da microbacia do Córrego Alegria em Uberaba-MG José Luiz Rodrigues Torres, Tobias Rodrigues da Silva, Francienne Góis Oliveira, Gustavo Silva Araújo, Adelar José Fabian

por dois ou mais cursos de água de $1^{\text {a }}$ ordem; um de $3^{\mathrm{a}}$ ordem é formado por dois ou mais cursos de segunda ordem.

\section{Resultados e discussão}

De uma forma geral, os resultados demonstraram que as condições sócio-econômico e ambientais na microbacia do Córrego Alegria são razoáveis e mostram uma preocupação da população na área com as questões ambientais (Tabela 3).

Tabela 3. Cálculo do percentual de deterioração social, econômica, sócio-econômica, tecnológica e ambiental na microbacia Córrego Alegria, em Uberaba-MG.

\begin{tabular}{lccccc}
\hline \multirow{2}{*}{ Diagnóstico } & \multicolumn{5}{c}{ Valores significativos } \\
\cline { 2 - 6 } & Mínima & Máxima & Moda & Equação da reta & Deterioração (\%) \\
\hline Social & 51 & 283 & 158 & $\mathrm{Y}=0,4310 \mathrm{X}-21,9810$ & 46 \\
Econômico & 20 & 66 & 42 & $\mathrm{Y}=2,1739 X-43,4780$ & 48 \\
Tecnológico & 17 & 51 & 28 & $\mathrm{Y}=2,9412 X-50,0004$ & 32 \\
Sócio-econômico & 88 & 400 & 225 & $\mathrm{Y}=0,3205 X-28,2040$ & 44 \\
Ambiental & 24 & 48 & 28 & $\mathrm{Y}=4,1666 \mathrm{X}-99,9984$ & 15 \\
\hline
\end{tabular}

Para o fator social, foi encontrado um índice de $46 \%$ de deterioração, valor este considerado médio para o local de estudo (Gráfico 1). Algumas características obtidas com a aplicação dos questionários não justificam o índice encontrado, pois obtevese um nível de médio para alto de escolaridade por núcleo familiar, baixa quantidade de residentes em cada propriedade, ótima qualidade de moradia e consumo de alimentos com uma variação rica no cardápio.
A deterioração para o fator econômico (FE) calculada foi $48 \%$, sendo considerada média e revela a dificuldade enfrentada pelo homem do campo em administrar a propriedade (Gráfico 2). Dentre as variáveis analisadas, na produção identificou-se que a exploração principal é de gado bovino para corte e leite, com produtividade de média a alta, além de aves e suínos para consumo próprio. Na área, a renda bruta aproximada das propriedades varia entre 5 a

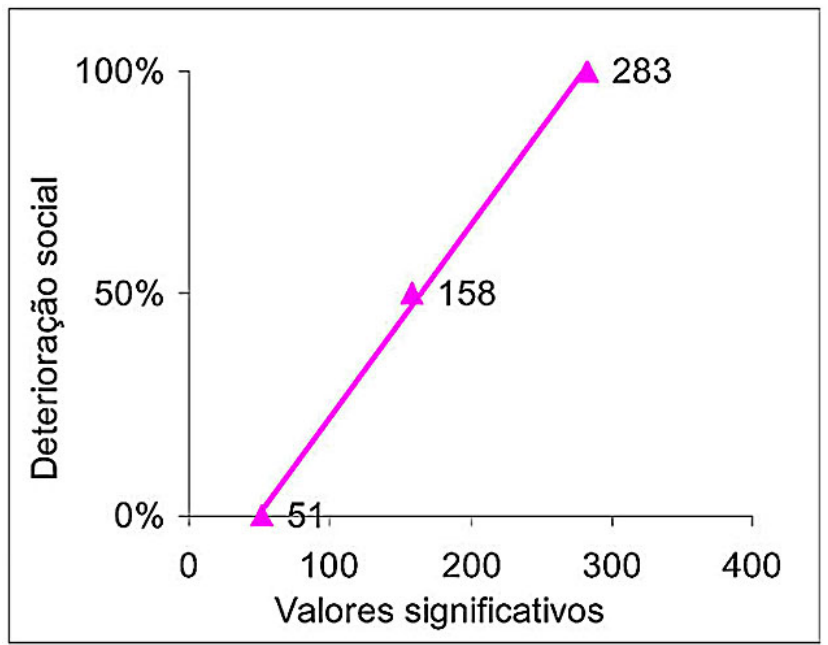

Gráfico 1. Deterioração social da microbacia do Córrego Alegria.

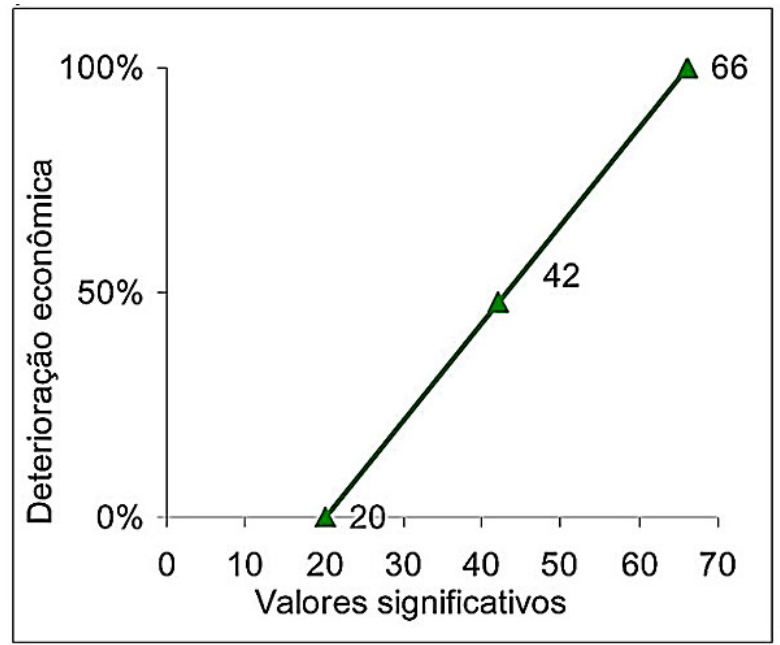

Gráfico 2. Deterioração econômica da microbacia do Córrego Alegria. 
15 salários mínimos, todos tem assistência técnica e são cooperados. As pastagens são formadas, rotacionadas e cavalos são utilizados para o trabalho com bovinos, contudo existem áreas mecanizadas na produção de grãos (milho e soja).

A deterioração do fator tecnológico (FT) foi 32 \% (Gráfico 3). Este fator apresentou um baixo valor, devido principalmente ao tipo de atividade econômica desenvolvida na área, que é a exploração de bovino de corte e leite, pois não utiliza grande aporte tecnológico e maquinário como ocorre em outras atividades. Para o cálculo da deterioração sócio-econômica (SE) utilizou-se o índice do FS +
FE + FT, com o qual obteve-se uma deterioração de 44 \% (Gráfico 4). Este valor revela limitação nas condições de vida do pequeno produtor e demais elementos da população.A deterioração ambiental (DA) calculado foi de 15 \% (Gráfico 5), que é um baixo índice de deterioração ambiental devido à preservação de nascentes, ausência de voçorocas e o desenvolvimento racional do uso dos recursos. $\mathrm{Na}$ microbacia estão presentes algumas propriedades rurais que desenvolvem atividades alternativas de geração de renda aliada à preservação ambiental, dentre elas, pesque-pague e produção orgânica de leite (com selo de qualidade).

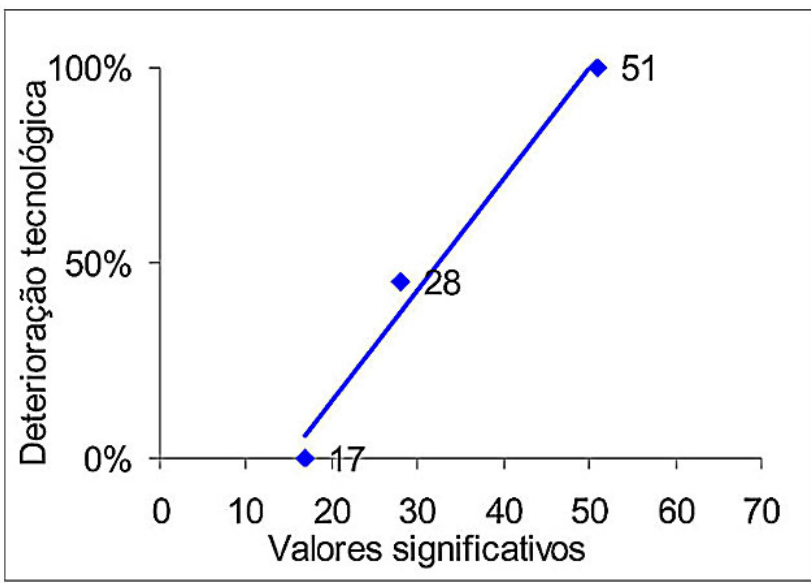

Gráfico 3. Deterioração tecnológica da microbacia do Córrego Alegria.

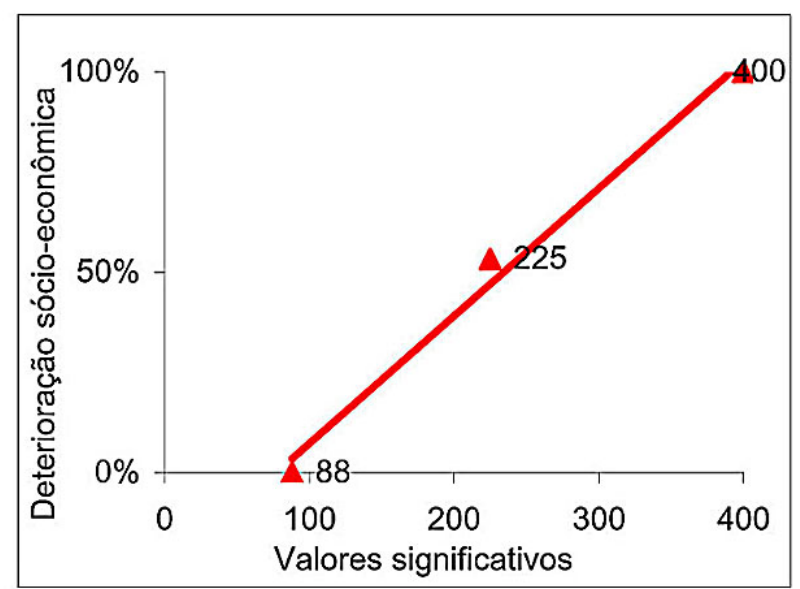

Gráfico 4. Deterioração sócio-econômica da microbacia do Córrego Alegria.

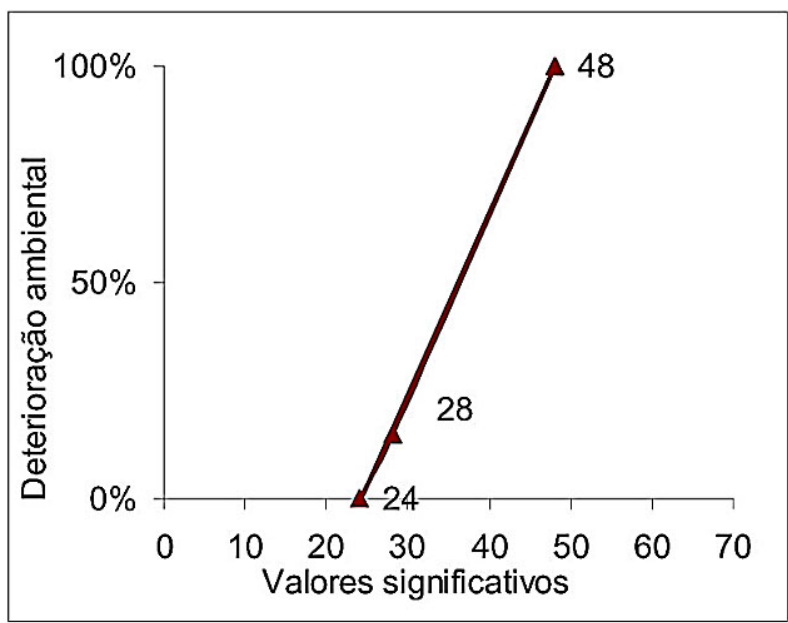

Gráfico 5. Deterioração ambiental da microbacia do Córrego Alegria. 
Diagnostico socioeconômico, ambiental e avaliação das características morfométricas da microbacia do Córrego Alegria em Uberaba-MG José Luiz Rodrigues Torres, Tobias Rodrigues da Silva, Francienne Góis Oliveira, Gustavo Silva Araújo, Adelar José Fabian

Para conservação do solo foram desenvolvidas medidas estruturais que funcionam como contendores de água, chamados bolsões. A construção de bolsões distribuídos por toda a área na microbacia é resultado dos programas ambientais iniciados após o acidente ferroviário ocorrido na microbacia, em 10 de junho de 2003, onde uma composição composta por três locomotivas e 33 vagões, tiveram 18 vagões descarrilados (Figura 4). Oito transportavam 381 toneladas de metanol; cinco, 245 toneladas de octanol; dois, 94 toneladas de isobutanol e três, 147 toneladas de cloreto de potássio, além de um vagão carregado de metanol explodiu, causando incêndio no local.

O local do acidente fica localizado a 1,2 km do rio Uberaba e a oito km do ponto de captação da rede municipal de abastecimento de água, o que causou desabastecimento e falta d'água na cidade de Uberaba por 10 dias consecutivos. Após o acidente percebe-se o aumento da preocupação ambiental tanto dos residentes da microbacia, quanto dos órgãos diretamente relacionados com a questão ambiental, além de uma maior fiscalização das ações no local.

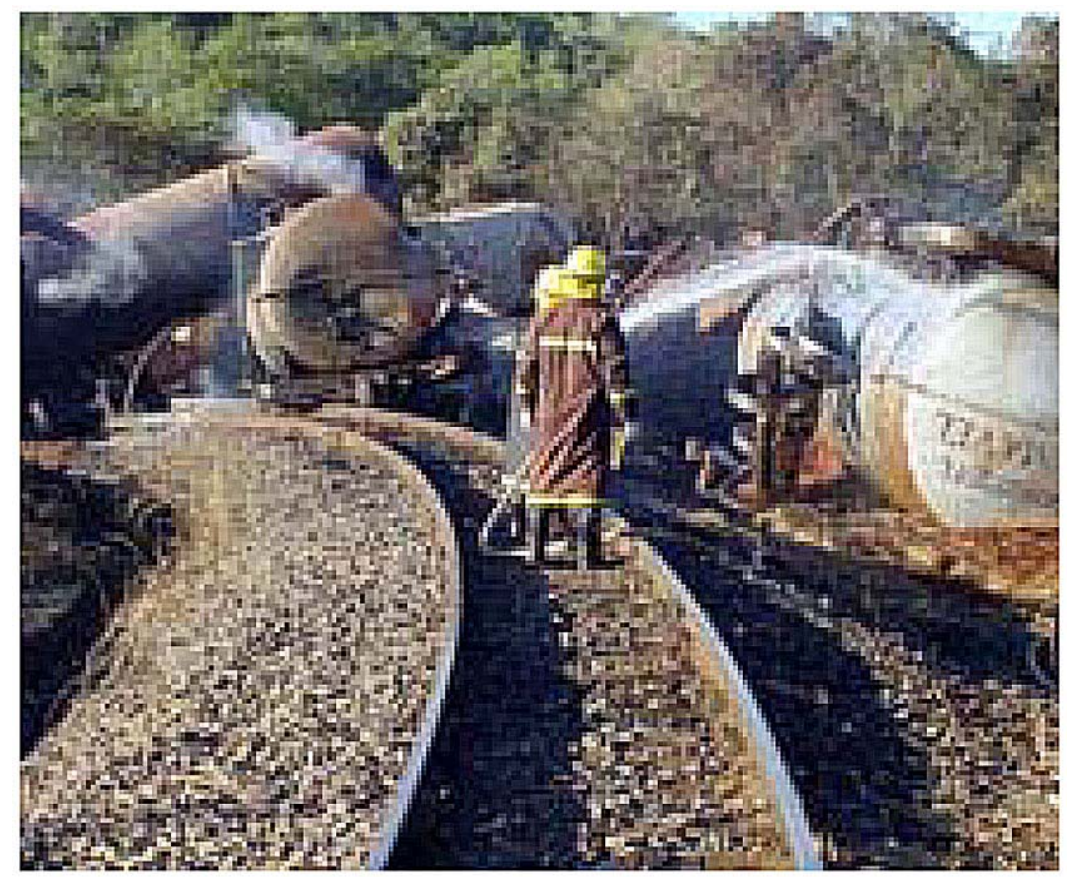

Figura 4. Acidente de trem ocorrido em junho de 2003 na microbacia do córrego Alegria.

Cruz (2003) em sua revisão destaca que a bacia do rio Uberaba possuia na decada de 80 , aproximadamente $41 \%$ de vegetação natural (cerrado), $46,8 \%$ de pastagens, $11,3 \%$ de culturas de ciclo curto e menos de $1 \%$ de terras urbanizadas, praticamente não existindo vegetação ciliar. Semelhantemente, a cobertura vegetal existente na microbacia do Córrego Alegria vem diminuindo ao longo dos anos $(37,04 \%)$, conforme descrito pela SEMEA (2004) e comprovada pelos questionários aplicados junto aos moradores locais, destes apenas 36,6\% (202,78 ha) são consideradas área de preservação permanente (APP) (Figura 1). Abdala (2005), em um estudo realizado na mesma época, comprova a diminuição da cobertura vegetal na APA do rio Uberaba, local onde está inserida a microbacia do córrego Alegria, e destaca que o uso do solo existente na bacia do alto curso do rio Uberaba é um misto de cerrado, pastagem e culturas, localizadas de acordo com atividades agrícolas desenvolvidas em cada propriedade. Nesta área as pastagens nativas e/ou cultivadas correspondem a $25 \%$ da área, as culturas em desenvolvimento inicial a13\%, e as culturas avançadas (cultivos anuais) a $5 \%$ do total da área. Todos os estudos chegaram a uma mesma conclusão, que o uso inadequado do solo na bacia ou microbacia tem gerado deterioração 
da ambiência, visto que ocorre aumento de áreas sem cobertura vegetal nativa e diminuição de áreas de preservação permanente (APP).

Na tabela 4 encontram-se os índices morfométricos da microbacia. A hierarquia fluvial consiste no processo de se estabelecer a classificação de determinado curso de água no conjunto total da bacia hidrográfica na qual se encontra. Estas classes receberam um valor referente ao grau de ordenação a que pertenciam os canais dispostos na carta base tornando possível sua hierarquização Segundo as Leis de Horton, a ordem do curso de água é uma medida da ramificação dentro de uma bacia.

Tabela 4. Índices morfométricos da microbacia do córrego Alegria.

\begin{tabular}{lcc} 
Índices Morfométricos & Unidade & Valores \\
\hline Área & $\mathrm{Km}^{2}$ & 15,39 \\
\hline Perímetro & $\mathrm{Km}$ & 13,90 \\
Comprimento rede de drenagem principal & $\mathrm{Km}$ & 8,52 \\
Comprimento $1^{\mathrm{a}}$ ordem & $\mathrm{Km}$ & 8,58 \\
Comprimento $2^{\mathrm{a}}$ ordem & $\mathrm{Km}$ & 8,52 \\
Comprimento total & $\mathrm{Km}$ & 17,10 \\
Maior largura & $\mathrm{Km}$ & 2,50 \\
Maior comprimento & $\mathrm{Km}$ & 8,20 \\
Largura média & $\mathrm{Km}$ & 1,22 \\
Amplitude altimétrica & $\mathrm{M}$ & 100 \\
Coeficiente de compacidade (Kc) & - & 0,98 \\
Fator forma (Kf) & - & 0,15 \\
Densidade de drenagem & $\mathrm{km} / \mathrm{km}$ & 1,10 \\
Sinuosidade do curso principal & - & 1,30 \\
Declividade da bacia & $\%$ & 1,20 \\
Declividade do curso principal & $\%$ & 1,17 \\
Índice de circularidade (Ic) & - & 0,60 \\
Somatório dos comprimentos dos cursos & $\mathrm{Km}$ & 37,93 \\
Eqüidistância entre curvas & $\mathrm{M}$ & 10,00 \\
Declividade média da bacia & $\%$ & 1,95 \\
Coeficiente de rugosidade (Rn) & - & 2,41 \\
\hline & &
\end{tabular}

Um curso de água de primeira ordem é um tributário sem ramificações; um curso de água de segunda ordem é um tributário formado por dois ou mais cursos de água de $1^{\text {a }}$ ordem; um de $3^{\text {a }}$ ordem é formado por dois ou mais cursos de segunda ordem; e, genericamente, um curso de água de ordem n é um tributário formado por dois ou mais cursos de água de ordem $(\mathbf{n}-\mathbf{1})$ e outros de ordens inferiores (STRAHLER, 1952).
A análise dos índices físicos e morfométricos da microbacia mostram que o Córrego Alegria possui um curso de água pequeno, sendo considerado de $3^{\circ}$ ordem (Figura 5). A sinuosidade do curso é baixa possibilitando maior velocidade na dispersão de poluentes, embora possua baixa declividade do curso d'água principal e da bacia. 
Diagnostico socioeconômico, ambiental e avaliação das características morfométricas da microbacia do Córrego Alegria em Uberaba-MG José Luiz Rodrigues Torres, Tobias Rodrigues da Silva, Francienne Góis Oliveira, Gustavo Silva Araújo, Adelar José Fabian

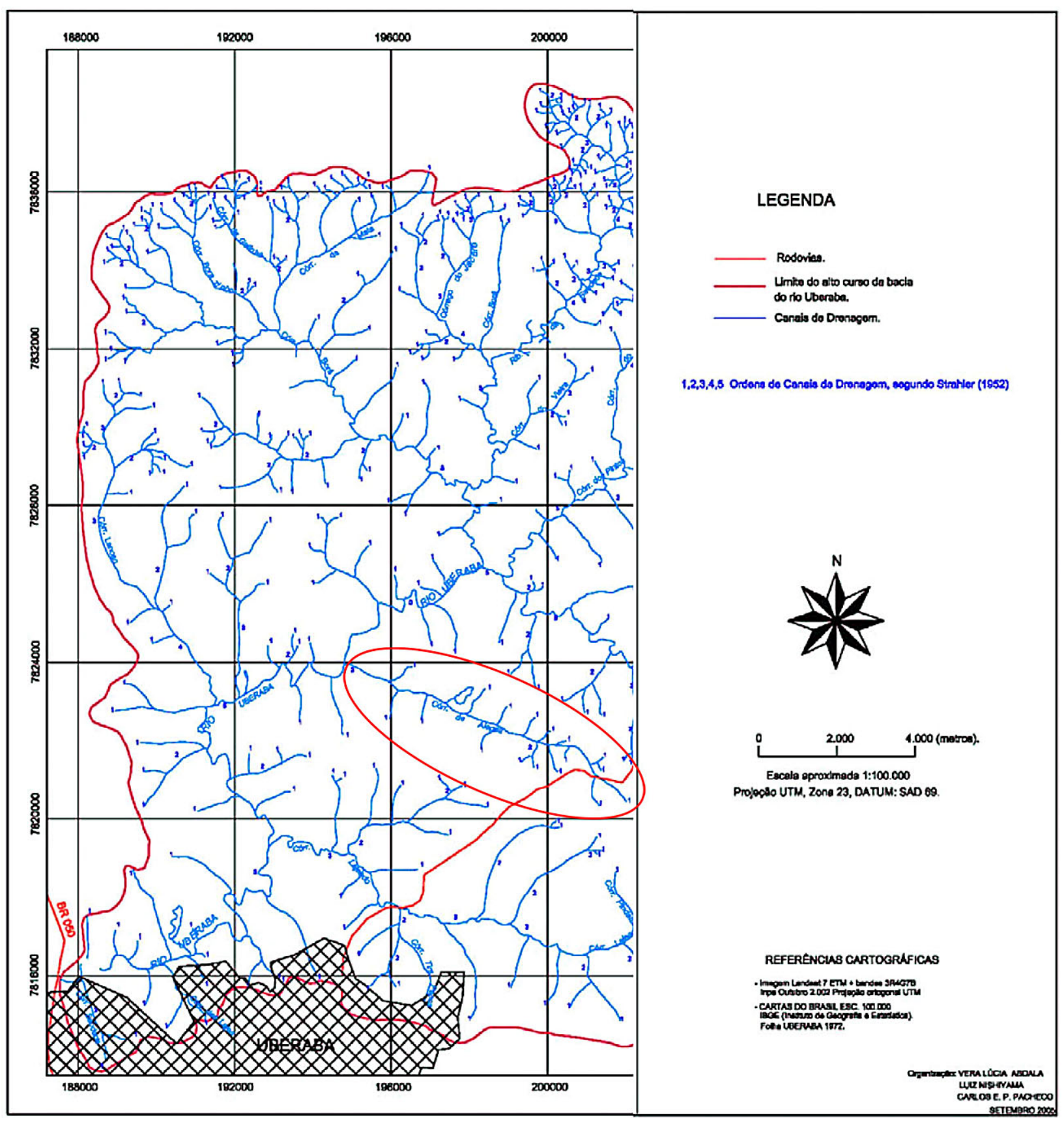

Figura 5. Mapa da ordem dos canais de drenagem do alto curso do rio Uberaba-MG, onde está inserido o Córrego Alegria (em destaque).

Modificado de Abdala (2005)

O fator forma (Kf) indica o formato da microbacia, no caso do Córrego Alegria é considerado alongado, o qual facilita o escoamento de água. Este fator associado à densidade de drenagem $(\mathrm{Dd})$ indicará a eficiência da drenagem na bacia, que é definida como a relação entre o comprimento total dos cursos de água e a área de drenagem e é expressa em $\mathrm{km} / \mathrm{km}^{2}$. Com um fator $\mathrm{Kf}$ pequeno $(0,15)$ associado a uma densidade de drenagem de $1,10 \mathrm{~km} /$ $\mathrm{km}^{2}$, que é um índice baixo, pode-se afirmar que o formato alongado da microbacia, diminui o risco de ocorrer enchentes na área, apesar de ser um córrego 
pequeno. A microbacia apresenta baixa densidade de drenagem possivelmente em razão dos seus dados serem extraídos de cartas topográficas, que geralmente não representam adequadamente os tributários de primeira ordem.

O coeficiente de compacidade é um número adimensional que varia com a forma da bacia, independentemente do seu tamanho. Quanto mais irregular for à bacia, tanto maior será o coeficiente de compacidade. Quando menor que um $(1,00)$ for coeficiente calculado, menos susceptível às enchentes será a microbacia. Porém este fator deve analisado conjuntamente com os outros fatores calculados, pois se analisado isoladamente para o Córrego Alegria indicará que a microbacia está sujeita a enchentes, o que é uma interpretações equivocada. Resultados semelhantes foram obtidos por Cardoso et al (2006), que fizeram a caracterização morfométrica da bacia hidrográfica do rio Debossan, Nova Friburgo, RJ a partir de alguns parâmetros físicos. Observaram coeficiente de compacidade elevado $(1,58)$, pequeno fator de forma $(0,33)$ e índice de circularidade $(0,39)$. A densidade de drenagem obtida para a bacia foi elevada $\left(2,36 \mathrm{~km} / \mathrm{km}^{2}\right)$. Destacaram que a forma mais alongada da bacia indica que a precipitação pluviométrica sobre ela se concentra em diferentes pontos, concorrendo para amenizar a influência da intensidade de chuvas, as quais poderiam causar maiores variações da vazão do curso d'água e consequentemente as enchentes.

O valor calculado para o índice de circularidade (Ic) foi de 0,60 , o que confirma o baixo risco de ocorrer enchentes na área em estudo, pois quanto mais próximo este valor tiver de 1,00, mais propensa a enchentes será a área. Alcântara e Amorim (2005) observaram uma densidade de drenagem maior $\left(1,47 \mathrm{~km} / \mathrm{km}^{2}\right)$ destacando a forma circular da bacia, com um índice de circularidade (Ic) menor $(0,44)$, comprovando que a microbacia em estudo não era susceptível a enchentes.

A sinuosidade do curso de água principal é um fator controlador da velocidade de escoamento e representa a relação entre o comprimento do rio principal e o comprimento de seu talvegue. A sinuosidade do curso é baixa $(1,3)$ possibilitando maior velocidade na dispersão de poluentes, associado à baixa declividade do curso de água principal $(1,17)$ e da bacia $(1,20)$, indicam que a água escoa com baixa velocidade, que diminuem a possibilidade de ocorrência de processos erosivos ao longo e no leito do córrego.

O Coeficiente de Rugosidade (RN) é um parâmetro que direciona o uso potencial da terra com relação às suas características para agricultura, pecuária, pecuária/floresta ou floresta. O RN é a relação entre a densidade de drenagem e a declividade média da microbacia, o baixo valor obtido indica que a área tem aptidão para agricultura.

\section{CONCLUSÕES}

- Na microbacia do Córrego Alegria, as questões relacionadas aos fatores sociais, econômicos e ambientais, bem como os índices morfométricos não demonstram índices preocupantes de deterioração, possuindo aptidão para agricultura;

- A caracterização morfométrica da microbacia do Córrego Alegria descreve uma forma mais alongada, sendo comprovado pelo índice de circularidade, coeficiente de compacidade e fator de forma;

- A densidade de drenagem é de 1,10 km/ $\mathrm{km}^{2}$, que associados à baixa declividade da microbacia, causam poucos problemas com erosão ao longo e no leito do Córrego;

\section{REFERÊNCIAS}

ABDALA, V.L. Zoneamento Ambiental da Bacia do Alto Curso do Rio Uberaba-MG como Subsídio para a Gestão do Recurso Hídrico Superficial. 2005, 73 p. (Dissertação de Mestrado). Universidade Federal de Uberlândia - UFU, 2005.

ALCANTARA, E.H.; AMORIM, A.J. Análise morfométrica de uma bacia hidrográfica costeira: um estudo de caso. Uberlândia-MG, Caminhos da Geo- 
Diagnostico socioeconômico, ambiental e avaliação das características morfométricas da microbacia do Córrego Alegria em Uberaba-MG José Luiz Rodrigues Torres, Tobias Rodrigues da Silva, Francienne Góis Oliveira, Gustavo Silva Araújo, Adelar José Fabian

grafia 7 (14) 70-77, fev./2005.

ARAÚJO, G.S; OLIVEIRA, F.G.; SILVA, T.R.; TORRES, J.L.R; FABIAN, A.F. IN: Environmental diagnosis and socieconomic of Stream Limo microbasin in Uberaba-MG. International Symposium on Land Degration and Desertification, Uberlândia-MG, Anais... Uberlândia-MG, 2005, p. 65-66.

CARDOSO, C.A.; DIAS, H.C.T.; SOARES, C.P.B; SEBASTIÃO VENÂNCIO MARTINS, S.V. Caracterização morfométrica da bacia hidrográfica do rio Debossan, Nova Friburgo, RJ. Revista Árvore, vol.30 no.2 Viçosa Mar./Apr. 2006.

CHRISTOFOLETTI, A. Análise morfométrica de bacias hidrográficas. Noticia Geomorfológica, 9 (18), p. 35-64, 1969.

CHRISTOFOLETTI, A. Geomorfologia. São Paulo: Edgard Blucher. 1974. 150p.

CRUZ, B.S. Diagnóstico ambiental da bacia hidrográfica do rio Uberaba. USP-Campinas/SP, 2003, 180p. (Tese de Doutorado).

CARDOSO, C.A.; DIAS, H.C.T.; SOARES, C.P.B; SEBASTIÃO VENÂNCIO MARTINS, S.V. Caracterização morfométrica da bacia hidrográfica do rio Debossan, Nova Friburgo, RJ. Rev. Árvore, v.30, n.2, Viçosa Mar./Apr. 2006.

EMBRAPA - Empresa Brasileira de Pesquisa Agropecuária. Serviço Nacional de Levantamento e Conservação de Solos - Levantamento de reconhecimento de meia intensidade dos solos e avaliação da aptidão agrícola das terras do Triângulo Mineiro. Rio de Janeiro, 1982. 562p.

FABIAN, A.J.; CANDIDO, H.G.; CRUZ, O.C. Dossiê de ambiência do bairro rural da Capelinha do Barreiro. Prefeitura Municipal de Uberaba, 2002, 16 p.

FABIAN, A.J. \& TORRES, J.L.R. Caracterização da paisagem para planejamento conservacionista em microbacia hidrográfica de Uberaba-MG. In: XXIX
Congresso Brasileiro da Ciência do Solo, Ribeirão Preto-SP. Anais... Ribeirão Preto-SP, 2003, p. 3536.

GOMES, I. A. et. al. Levantamento de reconhecimento de média intensidade e

aptidão agrícola dos solos do Triângulo Mineiro, Rio de Janeiro, 1982, 118p.

HORTON, R. Erosional development of streams and their drainage basins: hidrophysical approach to quatitative morphology. New York: Geological Society of American Bulletin, 1945, v.56, p. 807813.

LIMA, J.R.; BARBOSA , M.P.; NETO, J.D. Avaliação do incremento de açudes e sua relação com o uso do solo, através do uso de imagens TM/Landsat 5: um estudo de caso. Revista Brasileira de Engenharia Agrícola e Ambiental, Campina Grande-PB v.2, n.2, p. 243-245, 1998.

MARTINS,M.S.M.; SOUSA, J.S.; CUNHA, M.R.; TORRES, J.L.R; FABIAN, A.F. IN: Environmental diagnosis and socieconomic of Stream Limo microbasin in Uberaba-MG. International Symposium on Land Degration and Desertification, Uberlândia-MG, Anais... Uberlândia-MG, 2005, p. 63.

NISHIYAMA, L. Geologia do Município de Uberlândia e áreas adjacentes.

Sociedade \& Natureza, Uberlândia, v.1, n.1, p. 915, 1989.

PIRES, J.S.R.; SANTOS, J.E. Bacias hidrográficas: integração entre meio ambiente e desenvolvimento. Ciência Hoje. Rio de Janeiro, v.19, n.110, p. 40-45, 1995.

ROCHA, J. S. M. Manual de projetos ambientais. Santa Maria: UFSM, 1997. 423p.

ROCHA, J.S.M. da \& KURTS, S.M.J.M. Manual de manejo integrado de bacias hidrográficas. $4^{\mathrm{a}} \mathrm{ed}$. 
Santa Maria: UFSM/CCR, 2001.120 p.

ROCHA, J.S.M.; KURTZ, S.M.J.M. Curso de Manejo Integrado de Bacias Hidrográficas: aplicações técnicas avançadas em diagnósticos físicos conservacionista, sócio-econômico, ambiental. Santa Maria: Universidade Federal de Santa Maria - UFSM, 2003.

SANTOS, G.J.S.; ZANUTO, G.; TORRES, J.L.R.; FABIAN,A.J. Diagnóstico sócio-econômico ambiental da microbacia do Córrego Mangabeira, em Uberaba-MG. In: XXX Congresso Brasileiro de Ciência do Solo, SBCS, Recife-PE. Anais... Recife-PE, 2005, p. 34.

SECRETARIA MUNICIPAL DE MEIO AMBIENTE (SEMEA). Diagnóstico Ambiental da Área de Proteção Ambiental (APA) do Rio Uberaba, 2004, 127 pgs.

SILVA, A.L.; SILVA, E.C.; RESENDE, E.F.; PESSOA, E.J.; TORRES, J.L.R; FABIAN, A.F. IN: Environmental diagnosis and socieconomic of Stream Limo microbasin in Uberaba-MG. International Symposium on Land Degration and Desertification, Uberlândia-MG, Anais... Uberlândia-MG, 2005, p. 67.

SOUZA, Ê. R.; FERNANDES, M. R. Sub-bacias hidrográficas: unidades básicas para o planejamento e a gestão sustentáveis das atividades rurais. Informe Agropecuário. Belo Horizonte, v.21, n.27, p. 15-20, nov./dez. 2000.

STRAHLER, A .N. 1952. Hypsometric analysis of erosional topography. Geol. Soc. America Bulletin, 63, p. 1117-1142.

TUCCI, C.E.M.; SILVEIRA, A.L.L. et al. Hidrologia: Ciência e aplicação. $3^{\mathrm{a}}$ ed. $1^{\mathrm{a}}$ reimpressão, Porto Alegre: Ed. da UFRGS/ABRH, 2004. 943p.

UBERABA EM DADOS, Prefeitura Municipal de Uberaba. Edição 2005, 75p., ano Base 2004.

VIANA, R.L.; RIBEIRO, G.A.; LIMA, G.S.; SOUZA, F.A.A.; GÓES, C.T. Considerações sobre a elaboração de um diagnóstico sócio-econômico e sócio-ambiental no entorno de uma unidade de conservação. In: XVI Congresso Brasileiro de Economia Domestica e IV Encontro Latino-Americano de Economia Doméstica, Viçosa-MG, ABED. Anais... Viçosa-MG, 2001, p. 717-723.

VILLELA, S.M.; MATTOS, A. Hidrologia aplicada. São Paulo: McGraw-Hill do Brasil, 1975. 245p. 